\title{
Activation of integrin- $\beta_{3}$-associated syk in platelets
}

\author{
Sibaji SARKAR ${ }^{\star}$, Michael M. ROONEY $\dagger$ and Susan T. LORD ${ }^{*}+t^{1}$ \\ *Department of Pathology and Laboratory Medicine, University of North Carolina, Chapel Hill, NC 27599, U.S.A., †Department of Chemistry, University of North \\ Carolina, Chapel Hill, NC 27599, U.S.A., and †Curriculum in Genetics and Molecular Biology, University of North Carolina, Chapel Hill, NC 27599, U.S.A.
}

Published data suggest that the tyrosine kinase syk participates in platelet signalling through the integrin $\alpha_{\text {IIb }} \beta_{3}$. Our data show an association of syk and integrin $\beta_{3}$ in immunoprecipitates from unstimulated and stimulated platelets. We detected syk in anti- $\beta_{3}$ precipitates and, conversely, $\beta_{3}$ in anti-syk precipitates. In vitro kinase assays with anti- $\beta_{3}$ precipitates demonstrated that syk activity was enhanced in ADP-stimulated platelets.

Key words: integrin $\alpha_{\mathrm{IIb}} \beta_{3}$, signal transduction, tyrosine kinase.

\section{INTRODUCTION}

Platelet activation is the first step of platelet aggregation. In the presence of an agonist such as ADP, thrombin, collagen or epinephrine, platelets are activated. One of the important consequences of platelet activation is alteration of the fibrinogen receptor integrin $\alpha_{\mathrm{II}} \beta_{3}$ to allow fibrinogen binding, in a process called 'inside-out' signalling. This signal is probably mediated by phosphorylation, as several cellular kinases, including src, syk, Vav and phosphoinositide 3-kinase, are activated by platelet activation [1-3].

Fibrinogen binding to activated integrin $\alpha_{\mathrm{II}} \beta_{3}$ mediates platelet aggregation. The events subsequent to fibrinogen binding are called 'outside-in' signalling. Results from different laboratories have demonstrated that syk and phosphoinositide 3-kinase are activated after the engagement of integrin $\alpha_{\mathrm{IIb}} \beta_{3}$, even in the absence of agonist [4,5]. Syk was activated when fibrinogen was allowed to bind to stirred platelets treated with an integrin$\alpha_{\text {II }} \beta_{3}$-activating antibody, LIBS6 [4]. The role of syk in outsidein signalling has been further documented in CHO cells transfected with integrin $\alpha_{\text {II }} \beta_{3}$ and syk. Syk activation in such cells was dependent on fibrinogen binding to integrin $\alpha_{\text {IIb }} \beta_{3}$ [6]. Truncation of the cytoplasmic domain of either the $\alpha_{\text {IIb }}$ or the $\beta_{3}$ subunit abolished syk activation [6]. These results suggest that syk is involved in both inside-out and outside-in signalling in platelets.

Results from two other laboratories have suggested a close relationship between integrin engagement, specifically the $\beta$ subunit, and syk activation. Yan et al. [7] demonstrated the association of integrin $\beta_{2}$ with syk in monocytes, and Gotoh et al. [8] found that antibody-induced cross-linking of integrin $\beta_{1}$ activates syk in myeloid cells.

If syk is involved in integrin- $\alpha_{\mathrm{II}} \beta_{3}$-mediated signalling, it should associate with the $\beta_{3}$ subunit of this receptor (henceforth called $\beta_{3}$ ), at least in the early stages of platelet aggregation. To test this hypothesis, we examined platelet lysates for $\beta_{3}$-syk complexes. Using immunoblot analysis of immunoprecipitates from platelet lysates, we demonstrated that syk associates with $\beta_{3}$ in unstimulated platelets, as well as in platelets stimulated with either ADP or thrombin in the presence of fibrinogen. At present, we do not know whether this association is direct or is mediated by any other intermediary molecule. We performed in vitro autokinase assays with $\beta_{3}$ immunoprecipitates and found that autophosphorylation of syk associated with $\beta_{3}$ was enhanced in response to platelet aggregation.

Part of this work was presented in the Keystone Symposium on Specificity in Signal Transduction (Lake Tahoe, NV, U.S.A.; March 1998).

\section{EXPERIMENTAL}

\section{Materials}

A monoclonal antibody to $\beta_{3}$, AP-3, used for immunoprecipitation was obtained from a previously described cell line [9] supplied by Dr. Peter J. Newman (Blood Institute, Milwaukee, WI, U.S.A.). A polyclonal antibody to $\beta_{3}$, called Fire and Ice, used for immunoprecipitation and Western analysis was a gift from Dr. Peter J. Newman [10]. The polyclonal antibodies to syk used in Western analysis and immunoprecipitation were purchased from Upstate Biotech and Santa Cruz Biotech respectively. A monoclonal antibody to syk used for immunoprecipitation and the SuperSignal Chemiluminescent Substrate for Western blot detection were purchased from Pierce. Horseradish peroxidase (HRP)-conjugated goat anti-rabbit and anti-mouse secondary antibodies and purified human plasma fibrinogen were purchased from Calbiochem. Protein A/G-conjugated agarose beads were from Santa Cruz, and PVDF membrane was from Millipore. Piceatannol was purchased from Biomol Research Laboratories. Human $\alpha$-thrombin was a gift from Dr. Frank Church (University of North Carolina, Chapel Hill, NC, U.S.A.). ADP was purchased from Chrono-log. $\left[\gamma^{-32} \mathrm{P}\right]$ ATP was purchased from NEN. All other chemicals, including isotype-matched control antibodies, were purchased from Sigma.

\section{Isolation and purification of human platelets}

Platelets were purified as described [11] from the whole blood of volunteers who had abstained from using aspirin for at least 10 days. Briefly, platelet-rich plasma was obtained by centrifugation of the collected blood at $200 \mathrm{~g}$ for $25 \mathrm{~min}$ at ambient temperature. Platelets were pelleted from the supernatant by centrifugation at $800 \mathrm{~g}$ for $20 \mathrm{~min}$ at ambient temperature. Platelets were resuspended in Tyrode's buffer, pH 7.2 [10 mM Hepes, $135 \mathrm{mM}$ $\mathrm{NaCl}, 2.7 \mathrm{mM} \mathrm{KCl}, 12 \mathrm{mM} \mathrm{NaHCO}_{3}, 5.5 \mathrm{mM}$ glucose, $2 \%$ (w/v) BSA (fraction V; Miles Pentex), and passed through a

Abbreviations used: $\beta_{3}$, integrin $\beta_{3}$ subunit; TBST, Tris-buffered saline/Tween; HRP, horseradish peroxidase.

1 To whom correspondence should be addressed: Department of Pathology and Laboratory Medicine, CB\# 7525, Brinkhous-Bullit Bldg, University of North Carolina, Chapel Hill, NC 27599-7525, U.S.A. (e-mail stl@med.unc.edu). 
Sepharose CL-2B column equilibrated with Tyrode's buffer. The platelets were eluted in the same buffer and the density was measured using a Coulter Counter. Platelets were diluted to $5 \times 10^{8}$ platelets $/ \mathrm{ml}$ in Tyrode's buffer containing $1 \mathrm{mM} \mathrm{Ca}^{2+}$ and $2 \mathrm{mM} \mathrm{Mg}^{2+}$, and maintained at $37^{\circ} \mathrm{C}$.

\section{Platelet aggregation}

Platelets were incubated at $37^{\circ} \mathrm{C}$ at a final concentration of $1 \times 10^{8}$ platelets per $0.5 \mathrm{ml}$ in cuvettes in a Chrono-log aggregometer. Aggregation was initiated by the stepwise addition of $300 \mathrm{nM}$ human plasma fibrinogen and agonist (10 $\mu \mathrm{M}$ ADP or $0.5 \mathrm{unit} / \mathrm{ml}$ thrombin), followed by stirring. Aggregation was monitored as the increase in light transmission [11], and the aggregation reaction was stopped after $20 \mathrm{~s}$ by the addition of $125 \mu 1$ of ice-cold $5 \times$ lysis buffer (see below).

\section{Preparation of Triton-soluble fractions}

Triton-soluble fractions were prepared, as modified from the method of Clark and Brugge [12], in $1 \times$ lysis buffer [20 mM Tris/HCl, $\mathrm{pH} 7.4,1 \%(\mathrm{v} / \mathrm{v})$ Triton X-100, $5 \mathrm{mM}$ EGTA, $4 \mu \mathrm{g} / \mathrm{ml}$ leupeptin, $100 \mu \mathrm{g} / \mathrm{ml}$ PMSF, $4 \mu \mathrm{g} / \mathrm{ml}$ aprotinin and $1.2 \mathrm{mM}$ sodium vanadate]. Unstimulated platelets (incubated at $37^{\circ} \mathrm{C}$ with no addition and no stirring) or aggregated platelets $(500 \mu \mathrm{l})$ were added to $125 \mu \mathrm{l}$ of ice-cold $5 \times$ lysis buffer, mixed by gentle shaking and kept on ice for $1 \mathrm{~h}$. The sample was centrifuged at $15000 \mathrm{~g}$ for $10 \mathrm{~min}$ at $4{ }^{\circ} \mathrm{C}$, and the supernatant was collected; this fraction is the Triton-soluble fraction, which contains both the cytoplasmic and membrane-associated proteins. All fractions were stored at $-70{ }^{\circ} \mathrm{C}$.

\section{Immunoprecipitation}

Triton-soluble fractions were thawed on ice. Protein $A / G-$ agarose beads were washed with $1 \mathrm{ml}$ of ice-cold PBS. Portions of $40 \mu \mathrm{l}$ of beads were added to each fraction and tumbled for $1 \mathrm{~h}$ at $4{ }^{\circ} \mathrm{C}$. After centrifugation at $1000 \mathrm{~g}$ for $20 \mathrm{~s}$, the precleared supernatant was collected. Primary antibody was added and the sample was tumbled overnight at $4{ }^{\circ} \mathrm{C}$. Washed Protein $\mathrm{A} / \mathrm{G}$ beads $(40 \mu \mathrm{l})$ were added, and the sample was tumbled for $1 \mathrm{~h}$ at $4{ }^{\circ} \mathrm{C}$. After centrifugation at $1000 \mathrm{~g}$ for $1 \mathrm{~min}$, the supernatant was removed. The beads, which retain the immunoprecipitate, were washed four times with $1 \mathrm{ml}$ of ice-cold $1 \times$ lysis buffer. The washed beads were resuspended in $40 \mu \mathrm{l}$ of $2 \times$ reducing SDS/ PAGE sample buffer $[0.125 \mathrm{M}$ Tris $/ \mathrm{HCl}, \mathrm{pH} 6.8,4 \%$ (w/v) SDS, $20 \%(\mathrm{v} / \mathrm{v})$ glycerol, $10 \%(\mathrm{v} / \mathrm{v}) \beta$-mercaptoethanol and $0.1 \%$ (w/v) Bromophenol Blue], boiled for 5 min and centrifuged $(500 \mathrm{~g}$ for $20 \mathrm{~s})$, and the supernatants were applied to $10 \%(\mathrm{w} / \mathrm{v})$ polyacrylamide gels for SDS/PAGE [13]. For $\beta_{3}$ immunoprecipitations, $7.5 \mu \mathrm{g}$ of an anti- $\beta_{3}$ monoclonal antibody, an anti- $\beta_{3}$ polyclonal antibody or a respective isotype-matched control antibody was used. For syk immunoprecipitation, $4 \mu \mathrm{g}$ of an anti-syk monoclonal antibody, $1 \mu \mathrm{g}$ of an anti-syk polyclonal antibody or $4 \mu \mathrm{g}$ of an isotype-matched mouse antibody was used.

\section{Western blots}

Samples in reducing SDS sample buffer were boiled for $5 \mathrm{~min}$, run on SDS $/ 10 \%$-PAGE and transferred to a PVDF membrane. After blocking with Tris-buffered saline/Tween [TBST; $50 \mathrm{mM}$ Tris/ $\mathrm{HCl}, \mathrm{pH} 7.4,150 \mathrm{mM} \mathrm{NaCl}$ and $0.01 \%$ (v/v) Tween-20] containing $5 \%(\mathrm{w} / \mathrm{v})$ non-fat dried milk, the membrane was incubated overnight at $4{ }^{\circ} \mathrm{C}$ with the primary antibody diluted in $3 \%(\mathrm{w} / \mathrm{v})$ non-fat dried milk in TBST. After washing three times with TBST, the membrane was incubated for $1 \mathrm{~h}$ with goat anti- rabbit secondary antibody conjugated to HRP at 1:10000 dilution in $3 \%(\mathrm{w} / \mathrm{v})$ non-fat dried milk/TBST. After washing three times with TBST, the signal was developed with the Super Signal Chemiluminescent Substrate (Pierce) for $5 \mathrm{~min}$. Films were exposed for between $10 \mathrm{~s}$ and 2 min before being developed as described in the legends to the Figures. For syk immunodetection, $1 \mu \mathrm{g} / \mathrm{ml}$ anti-syk polyclonal antibody was used. For $\beta_{3}$ immunodetection, $10 \mu \mathrm{g} / \mathrm{ml}$ polyclonal anti- $\beta_{3}$ antibody [10] was used.

\section{In vitro kinase assay}

The incorporation of radiolabelled phosphate into $\beta_{3}$ immunoprecipitates was measured as described in $[14,15]$, with minor modifications. In brief, after washing with lysis buffer, the immunoprecipitates, prepared as described above, were washed with $1 \mathrm{ml}$ of ice-cold kinase buffer (50 mM Hepes, pH 7.4, $10 \mathrm{mM} \mathrm{MgCl}_{2}, 10 \mathrm{mM} \mathrm{MnCl} 2$ and $10 \mu \mathrm{M}$ sodium vanadate) and resuspended in $15 \mu \mathrm{l}$ of ice-cold kinase buffer. The kinase reaction was started by the addition of $15 \mu 1$ of ice-cold kinase buffer containing $4 \mu \mathrm{M}$ ATP and $10 \mu \mathrm{Ci}$ of $\left[\gamma^{32} \mathrm{P}\right] \mathrm{ATP}$. The mixture was placed at $30^{\circ} \mathrm{C}$ in a water bath. After $2 \mathrm{~min}$, the reaction was stopped by centrifugation for $20 \mathrm{~s}$. The supernatant was discarded and the beads were resuspended in $40 \mu \mathrm{l}$ of $2 \times$ reducing SDS/PAGE sample buffer, boiled for $5 \mathrm{~min}$, pelleted by centrifugation $(500 \mathrm{~g}$ for $20 \mathrm{~s}$ ), and subjected to SDS/10\%-PAGE. The proteins were transferred to a PVDF membrane, and an autoradiogram was developed. The membrane was then subjected to Western analysis for syk, as described above. In order to quantify the differences in autophosphorylation, the images in the blots were scanned using the program IS 2000 from Alpha Innotec.

\section{RESULTS}

\section{Association of $\beta_{3}$ and syk in platelets}

To examine whether the intracellular tyrosine kinase syk associates with $\beta_{3}$, we immunoprecipitated $\beta_{3}$ from Triton-soluble fractions of platelets and analysed the precipitates in immunoblots probed with an antibody to syk. As shown in Figure 1, a $72 \mathrm{kDa}$ protein was detected in immunoprecipitates prepared with either monoclonal antibody AP-3 (Figure 1A, lanes 1-3) or a polyclonal antibody to $\beta_{3}$ (Figure $1 \mathrm{~B}$, lanes $1-3$ ). The mobility of this band corresponded to that seen in syk immunoprecipitates (Figures 1A and 1B, lane 4). This co-precipitation of syk was specific, as shown in parallel immunoprecipitations with isotypematched antibodies (Figure 1C). Comparison of the AP-3 precipitate (lane 3) with the isotype-matched mouse IgG precipitate (lane 1) and of the polyclonal anti- $\beta_{3}$ precipitate (lane 4) with the isotype-matched rabbit IgG (lane 2) showed that the intensity of the $72 \mathrm{kDa}$ band was greater with the integrinspecific antibodies. The $10 \mathrm{~s}$ exposure time was chosen to minimize background, and emphasizes the differences between lanes 1 and 2, relative to lanes 3 and 4 (Figure 1C). These parallel immunoprecipitations demonstrated that the $72 \mathrm{kDa}$ protein was specific to the $\beta_{3}$ immunoprecipitates. A Western blot of identical samples run under similar conditions was developed with the secondary HRP-conjugated goat anti-rabbit antibody. No $72 \mathrm{kDa}$ band was detected in this blot (results not shown). These data support the conclusion that the $72 \mathrm{kDa}$ band found in the $\beta_{3}$ immunoprecipitates is syk.

These data demonstrate a specific association of syk and $\beta_{3}$ in anti- $\beta_{3}$ immune complexes prepared from platelet lysates. Further, syk was present in anti- $\beta_{3}$ immune complexes from all 

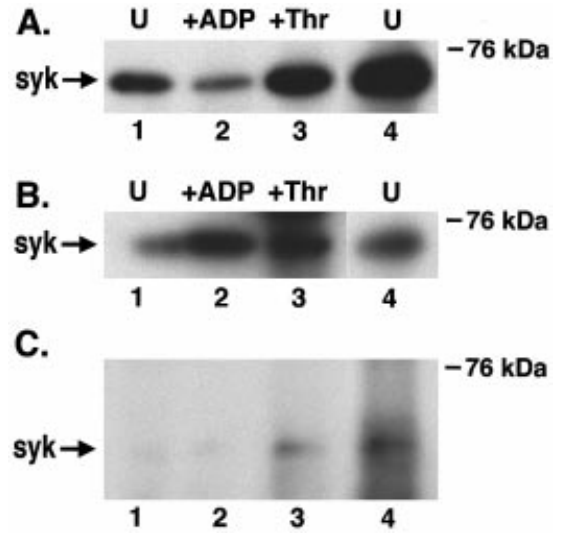

\section{Figure 1 Detection of syk in $\beta_{3}$ immunoprecipitates}

Immunoprecipitates prepared with an anti- $\beta_{3}$ monoclonal antibody, AP-3 (A, lanes 1-3), an anti$\beta_{3}$ polyclonal antibody (B, lanes 1-3) and isotype-matched control antibodies (C, lanes 1 and 2) were subjected to SDS/10\%-PAGE under reducing conditions. Blots were probed with a polyclonal antibody to syk and developed for $1 \mathrm{~min}(\mathbf{A}), 30 \mathrm{~s}(\mathbf{B})$ or $10 \mathrm{~s}(\mathbf{C})$. Samples in lanes 4 (U) were from unstimulated platelets. Stimulated platelet samples containing $300 \mathrm{nM}$ fibrinogen were stirred for $20 \mathrm{~s}$ following addition of $10 \mu \mathrm{M}$ ADP (lanes marked + ADP) or 0.5 unit/ml thrombin (lanes marked + Thr). Control immunoprecipitates were prepared with a polyclonal antibody to syk (lane 4 in $\mathbf{A}$ and $\mathbf{B}$ ), with isotype-matched mouse IgG1 (lane 1 in C), or with rabbit IgG (lane 2 in C). Lanes 3 and 4 in (C) contain anti- $\beta_{3}$ immunoprecipitates prepared as for lanes $U$ in $(\mathbf{A})$ and $(\mathbf{B})$ respectively. See the Experimental section for details.
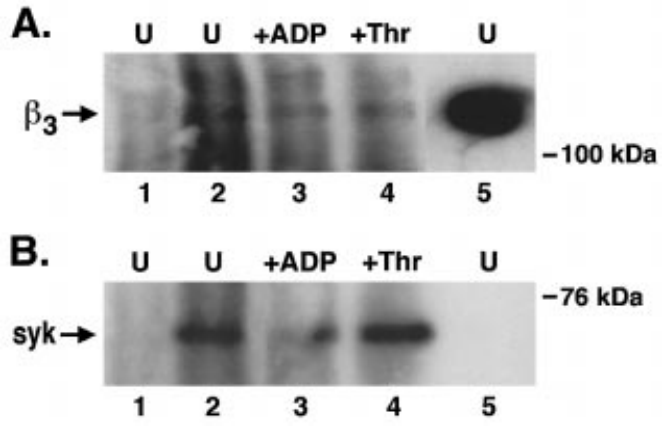

\section{Figure 2 Detection of $\beta_{3}$ in syk immunoprecipitates}

Immunoprecipitates prepared with an anti-syk monoclonal antibody (lanes 2-4), an isotypematched control antibody IgG2 ${ }_{2} \mathrm{~K}$ (lane 1 ) or the anti- $\beta_{3}$ monoclonal antibody AP-3 (lane 5 ; onethird loaded) were subjected to SDS/10\%-PAGE under reducing conditions. The blot in (A) was probed with the anti- $\beta_{3}$ polyclonal antibody and developed for $1 \mathrm{~min}$. Unstimulated platelets (lanes $\mathrm{U}$ ) and stimulated platelets [10 $\mu \mathrm{M} \mathrm{ADP} \mathrm{(lanes} \mathrm{marked} \mathrm{+} \mathrm{ADP)} \mathrm{or} 0.5 \mathrm{unit} / \mathrm{ml}$ thrombin (lanes marked + Thr)] were prepared as described in the legend to Figure 1. The blot was then stripped, probed with a polyclonal antibody to syk and developed for 1 min (B).

lysates (Figures 1A and 1B, lanes 1-3), demonstrating that this association is not dependent on platelet activation.

To confirm the association of syk with $\beta_{3}$, we performed the reverse analysis. Using similar Triton-soluble fractions, we prepared immunoprecipitates with an anti-syk monoclonal antibody and analysed these on immunoblots probed with the anti$\beta_{3}$ polyclonal antibody. The blot showed a band around $110 \mathrm{kDa}$ (Figure 2A) in samples prepared from unstimulated (lane 2), ADP-stimulated (lane 3) and thrombin-stimulated (lane 4) platelets. This band was not present in immunoprecipitates with an isotype-matched mouse antibody (lane 1). The mobility of this band corresponded to that in anti- $\beta_{3}$ immunoprecipitates (lane 5). A second immunoreactive band with a slightly lower mobility
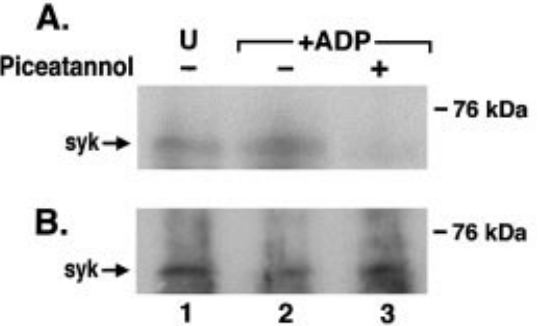

Figure 3 Autophosphorylation of syk in $\beta_{3}$ immunoprecipitates: inhibition by piceatannol

Platelets were incubated in the presence of $40 \mu \mathrm{g} / \mathrm{ml}$ piceatannol or DMSO for $15 \mathrm{~min}$ at $37^{\circ} \mathrm{C}$ prior to initiating platelet aggregation. $\beta_{3}$ was immunoprecipitated from Triton-soluble fractions with the anti- $\beta_{3}$ monoclonal antibody AP-3. Immunoprecipitates were resuspended in kinase buffer and autokinase activity was measured as described in the Experimental section. The phosphorylated proteins were resolved in SDS/10\%-PAGE under reducing conditions, transferred to a PVDF membrane and visualized by autoradiography $(\mathbf{A})$. Western analysis with an anti-syk antibody was then performed on the membrane $(\mathbf{B})$. Platelets were either unstimulated $(U)$ or were stimulated with $10 \mu \mathrm{M} \mathrm{ADP}$ (see the legend to Figure 1).

was present in the anti-syk samples (Figure 2, lane 2-4). We have not examined this protein further, but we (results not shown) and others [16] have seen a similar band in anti- $\beta_{3}$ immunoblots. We stripped this blot and re-probed it with an anti-syk antibody (Figure 2B), demonstrating that similar amounts of syk were immunoprecipitated from lysates of unstimulated, ADP-stimulated and thrombin-stimulated platelets.

Taken together, the results in Figures 1 and 2 demonstrate that $\beta_{3}$ and syk are associated in platelet lysates. Although the data show an association, they do not distinguish between a direct association and an indirect association mediated by other molecules.

\section{Syk autophosphorylation in $\boldsymbol{\beta}_{3}$ immunoprecipitates}

To determine whether the syk associated with $\beta_{3}$ was active, we assayed syk autophosphorylation in $\beta_{3}$ immunoprecipitates from unstimulated and ADP-stimulated platelets. Prior to initiating aggregation, we treated the platelets with the syk-selective inhibitor piceatannol ( $40 \mu \mathrm{g} / \mathrm{ml}$ in DMSO) or with DMSO for $15 \mathrm{~min}$ at $37^{\circ} \mathrm{C}$. This concentration of piceatannol has been shown to inhibit syk [17], but not the src-family kinase lyn. Kinase assays were performed on $\beta_{3}$ immunoprecipitates, the products were separated by SDS/PAGE, and radiolabelled bands were visualized after transfer to a PVDF membrane. As shown in Figure 3, autophosphorylation of a $72 \mathrm{kDa}$ protein was increased following ADP stimulation (compare lane 2 with lane 1 ), and this stimulation was inhibited by piceatannol (compare lane 3 with lane 2). The inhibition supports the conclusion that the autophosphorylated $72 \mathrm{kDa}$ band is syk. Furthermore, Western analysis of the membrane with an anti-syk antibody demonstrated that these differences were not due to changes in loading. As shown in Figure 3(B), the immunoreactive $72 \mathrm{kDa}$ band was least intense for the ADP-stimulated sample (Figure $3 \mathrm{~B}$, lane 2), demonstrating that sample loading minimized the increased autophosphorylation seen with this sample (Figure 3A, lane 2).

To quantify the differences in autophosphorylation, we scanned the X-ray films from Figure 3. The intensity of each band in the autokinase assay was divided by that obtained for each band in the Western analysis. This ratio normalized the autophosphorylation of each band to the amount of the $72 \mathrm{kDa}$ protein. For the unstimulated sample the ratio was 0.25 , for the 
ADP-stimulated sample it was 0.38 and for the piceatannolpretreated sample it was 0.072 . Thus the ADP-stimulated autophosphorylation was 1.5 -fold greater than unstimulated autophosphorylation. The piceatannol-pretreated ADP-stimulated sample showed 5 times less autophosphorylation compared with the untreated ADP-stimulated sample. These results demonstrated that the $\beta_{3}$-associated syk activity was enhanced in response to ADP-stimulated aggregation, and that this stimulation was inhibited by pre-incubation with piceatannol.

\section{DISCUSSION}

Our results demonstrate that syk is associated with $\beta_{3}$ in unstimulated platelets, as well as in aggregated platelets. The $\beta_{3^{-}}$ associated syk was activated when platelets were stimulated with ADP in the presence of fibrinogen under aggregation conditions. Such an association is similar to the association of syk with antigen receptors in B-cells [18,19], where IgM-syk complexes were found to be associated in anti-IgM or anti-syk immunoprecipitates from unstimulated cells. Ligation of IgM transiently activates syk $[18,19]$, similar to the transient activation of syk following integrin $\alpha_{\mathrm{IIb}} \beta_{3}$ ligation in platelets [1,4,6]. Further examination of our data, comparing Figures 1(A) and 1(B) with Figure 2, indicates that the fraction of syk that co-precipitated with anti- $\beta_{3}$ was larger than the fraction of $\beta_{3}$ that coprecipitated with anti-syk antibody. This result is similar to that reported for the association of a src-family tyrosine kinase, fyn-T, with the T-cell-receptor-CD3 complex. Approximately $20 \%$ of fyn-T co-precipitated with anti-CD3 [20], while only $2-5 \%$ of CD3 was co-precipitated with anti-fyn antibody [21]. Thus our results recapitulate those obtained for ligand-mediated intracellular tyrosine kinase signalling in both T-and B-cells.

A functional link between the engagement of integrin $\alpha_{\mathrm{IIb}} \beta_{3}$ and syk activation has been demonstrated previously in platelets and transfected $\mathrm{CHO}$ cells [4,6]. Although others have tried to demonstrate an intracellular association between this integrin and syk [14], our data are the first to show this complex. The experiments [14] that did not co-precipitate integrin $\alpha_{\text {IIb }} \beta_{3}$ and syk were not described in detail, so it is difficult to identify the experimental differences that accounted for our success. We favour the possibility that our lysis conditions were optimal for co-precipitating this complex. It is well documented that lysis conditions are important in maintaining the association between signalling molecules. Yan et al. [7] were not able to detect the association of syk with either $\mathrm{p}^{58 \mathrm{c} \text {-fgr }}$ or $\mathrm{p}^{53 / 561 \mathrm{yn}}$ when neutrophils were lysed in radioimmunoprecipitation assay buffer, but these associations were detected when the cells were lysed in Triton X100 [7]. Further, these authors were able to co-immunoprecipitate integrin $\beta_{2}$ and syk in Triton lysates of neutrophils [7]. Thus it is reasonable to conclude that $\beta_{3}$ and syk associate in a complex that can be co-precipitated from platelets following lysis with Triton X-100, as described here, but cannot be co-precipitated under different lysis conditions.

Our results demonstrate that the autophosphorylation of $\beta_{3}$ associated syk was enhanced following stimulation under aggregation conditions, indicating that the $\beta_{3}$-associated syk was activated by outside-in signalling. Our data add to the results reported by Gao et al. [6]. They examined $\mathrm{CHO}$ cells transfected with integrin $\alpha_{\mathrm{II}} \beta_{3}$ and syk, and found that syk activation depended on $\alpha_{\mathrm{IIb}} \beta_{3}$ ligation. As syk did not co-precipitate with $\alpha_{\mathrm{II}} \beta_{3}$ in transfected $\mathrm{CHO}$ cells [6], we suggest that the syk $-\beta_{3}$ complex is more stable in platelets. This raises the possibility that the association of syk and $\beta_{3}$ is mediated by an intermediary molecule that is present in platelets, and which differs from intermediary molecules in $\mathrm{CHO}$ cells.

Further studies are necessary in order to assess the activation of $\beta_{3}$-associated syk in platelets. Nevertheless, the demonstration of an association between $\beta_{3}$ and syk in platelets is a major step towards understanding the role of integrin $\alpha_{\mathrm{II}} \beta_{3}$ and syk in platelet signalling, and more generally in describing the role of $\beta$ integrins in the specialized functions of cells of haematopoietic lineage.

We thank Dr. Peter J. Newman (The Blood Center of SE Wisconsin, Milwaukee, WI, U.S.A.) for kindly providing the anti- $\beta_{3}$ polyclonal antibody. This study was supported by NIH grants R01 HL 31048 and HL 45100 to S.T.L. S.S. is supported by a NIEH training grant (5-T32-ESO 7017-22). M.M.R. is supported by a predoctoral fellowship from the American Heart Association, NC affiliate.

\section{REFERENCES}

1 Clark, E. A., Shattil, S. J. and Brugge, J. S. (1994) Trends Biochem. Sci. 19 464-469

2 Cichowski, K., Brugge, J. S. and Brass, L. F. (1996) J. Biol. Chem. 271, 7544-7550

3 Poole, A., Gibbins, J. M., Turner, M., van Vugt, M. J., van de Winkel, J. G. J., Saito, T., Tybulewicz, V. L. J. and Watson, S. P. (1997) EMBO J. 16, 2333-2341

4 Clark, E. A., Shattil, S. J., Ginsberg, M. H., Bolen, J. and Brugge, J. S. (1994) J. Biol. Chem. 269, 28859-28864

5 Banfic, H., Tang, X.-W, Batty, I. H., Downes, C. P., Chen, C.-S. and Rittenhouse, S. E. (1998) J. Biol. Chem. 273, 13-16

6 Gao, J., Zoller, K. E., Ginsberg, M. H., Brugge, J. S. and Shattil, S. J. (1997) EMBO J. 16, 6414-6425

7 Yan, S. R., Huang, M. and Berton, G. (1997) J. Immunol. 158, 1902-1910

8 Gotoh, A., Takahira, H., Geahlen, R. L. and Broxmeyer, H. E. (1997) Cell Growth Differ. 8, 721-729

9 Newman, P. J., Allen, R. W., Kahn, R. A. and Kunicki, T. J. (1985) Blood 65 227-232

10 Burk, C. D., Newman, P. J., Lyman, S., Coller, B. S. and Poncz, M. (1991) J. Clin. Invest. 87, 270-276

11 Rooney, M. M., Parise, L. V. and Lord, S. T. (1996) J. Biol. Chem. 271, 8553-8555

12 Clark, E. A. and Brugge, J. S. (1993) Mol. Cell. Biol. 13, 1863-1871

13 Laemmli, U. K. (1970) Nature (London) 227, 680-685

14 Law, D. A., Nannizzi-Alaimo, L. and Phillips, D. R. (1996) J. Biol. Chem. 271, 10811-10815

15 Keely, P. J. and Parise, L. V. (1996) J. Biol. Chem. 271, 26668-26676

16 Jallu, V., Diaz-Ricart, M., Ordinas, A., Pico, M., Vezon, G. and Nurden, A. T. (1994) Eur. J. Biochem. 222, 743-751

17 Oliver, J. M., Burg, D. L., Wilson, B. S., McLaughlin, J. L. and Geahlen, R. L. (1994) J. Biol. Chem. 269, 29697-29703

18 Hutchcroft, J. E., Harrison, M. L. and Geahlen, R. L. (1992) J. Biol. Chem. 267, 8613-8619

19 Yamada, T., Taniguchi, T., Yang, C., Yasue, S., Saito, H. and Yamamura, H. (1993) Eur. J. Biochem. 213, 455-459

20 Thomas, S. M. and Brugge, J. S. (1997) Annu. Rev. Cell Dev. Biol. 13, 513-609

21 Gassman, M., Guttinger, M., Amrein, K. E. and Burn, P. (1992) Eur. J. Immunol. 22, 283-286

Received 1 October 1998/20 November 1998; accepted 21 December 1998 